\title{
FRONTEIRAS DA TRADUÇÃO EM CONTOS DE JOSÉ MONEGAL
}

\author{
FRONTIERS OF TRANSLATION IN MONEGAL JOSÉ TALES
}

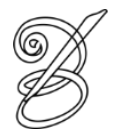 \\ Carlos García RIZZON* \\ Universidade Federal do Pampa, campus Jaguarão, Brasil
}

\begin{abstract}
Resumo: Por meio de estudos sobre a teoria da tradução - com o aporte teórico de Octavio Paz, Rosimary Arrojo, Haroldo de Campos, entre outros - e experimentando o ato tradutório, é tomada como objeto de estudo a obra em especial, o conto Arquetipo - de José Monegal, escritor uruguaio que, entre os anos de 1950 e 1968, publicou contos em seções literárias de jornais de Melo e Montevidéu, muitos deles hoje reunidos em diferentes edições. Com personagens ambientadas na paisagem pampiana da virada do século XIX para o XX, Monegal desenvolve uma literatura gauchesca que se opõe à tradição mítica e heroicaidealizada pela ficção, uma vez que trabalha com o humor e o grotesco, caracterizando uma figura pícara do gaúcho. Em seus textos, há a invenção de uma linguagem composta por regionalismos e marcas de oralidades, exigindo, na tradução para a língua portuguesa, recriações que acentuem o vocabulário e a pronúncia das falas que caracterizam suas personagens. A marca fronteiriça, tanto nos temas quanto na forma do texto, é outro aspecto presente nas suas narrativas, conferindo uma identidade particular que exige corruptelas da escrita padrão, o que possibilita, ao mesmo tempo, aproximações e distanciamentos entre espanhol e português. Dessa forma, conforme a teoria da tradução reconhece, ficam evidenciadas as porosidades, os trânsitos e os contrabandos literários e linguísticos disseminados na fronteira, território do encontro das diferenças. Essas são questões que se abordam no projeto de pesquisa Fronteiras da tradução literária, desenvolvido junto com estudantes bolsistas na Universidade Federal do Pampa.
\end{abstract}

Palavras-chave: Tradução. Fronteira. Regionalismo. Gauchesca. José Monegal.

Abstract: Throughout studies of the translation theory - with the theoretical contribution of Octavio Paz, Rosimary Arrojo, Haroldo de Campos, among others - and experimenting with the translation act, the object of study is the work - in particular, the short story Arquetipo - of José Monegal, an Uruguayan writer who, between the years of 1950 and 1968, published short stories in literary sections of newspapers of Melo and Montevideo, many of them today reunited in different editions. With characters set in the Pampas landscape from the turn of the nineteenth century to the twentieth, Monegal develops a gauchesque literature that opposes the mythical and heroic tradition idealized by fiction, since it works with the humor and the grotesque, characterizing a gaucho figure trickster. In their texts, the invention is a language composed of regionalisms and brads of orality, requiring, in the translation into the Portuguese language, recreations that accentuate the vocabulary and the ronunciation of the peeches that characterize its characters. The border marks, both in the themes and in the form of the text, is another aspect present in their narratives, conferring a particular identity that requires corruptions of the standar writing, which at the same time allows approximations and distances between Spanish and Portuguese. In this way, as the translation theory recognizes, the porosities, transits and literary and linguistic contraband disseminated on the border, territory of the encounter of differences, are evidenced. These are issues that are addressed in the research project Frontiers of literary translation developed together with scholarship students at the Universidade Federal do Pampa.

Keywords: Translation. Border. Regionalism. Gauchesca. José Monegal

RECEBIDO EM: 23/04/2019

ACEITO EM: 20/08/2019

PUBLICADO EM: 10/2019 


\section{A tradução na fronteira}

um histórico de mobilidade e redefinições, o que conforma um palimpsesto da
umaisagem, com aproximações e distanciamentos culturais no espaço fronteiriço que abarca essas nações. Houve épocas em que o território colonial brasileiro não compreendia o pampa gaúcho; em outros momentos, ele se estendeu até o rio da Prata. Desde o Tratado de Tordesilhas, a dimensão territorial do que seria colônia espanhola e do que pertenceria a Portugal foi questionável, pois os impérios ibéricos não possuíam as mesmas interpretações do que teria sido acordado. No transcurso dos tempos, os confrontos entre lusitanos e castelhanos, seja na Europa ou nas colônias americanas, renderam vários outros tratados e uma diversificação de traçados dos limites. Posteriormente, as independências das ex-colônias também provocaram novas definições territoriais e, no desejo de acentuar suas nacionalidades, reforçaram separações entre si com a execução de demarcações, procurando evidenciar os torrões pertencentes a cada nação.

Em meio a todo esse processo, as populações que ocuparam e se desenvolveram em 156 torno às fronteiras incertas e em contínuos movimentos de extensão e retração acabaram por criar uma mestiçagem - primeiro entre europeus e indígenas; mais tarde, agregados por africanos e, constantemente, entre habitantes de um e de outro lado das linhas divisórias -, o que originou um tipo social característico do lugar, o gaúcho.

Se é possível reconhecer elementos que permitem aproximações, sobretudo pelos aspectos culturais da identidade sul-rio-grandense que são compartilhados com os costumes e as tradições dos países do Prata, também é verdade que as diferenças de idioma que existem entre o Brasil e os seus vizinhos, muitas vezes, impedem relacionamentos mais concretos e aprofundados, dificultando que se tenha acesso, por exemplo, a importantes referências literárias de um lado para outro dos limites desses países.

Diante de questões como essas, é propósito da pesquisa Fronteiras da tradução literária - projeto desenvolvido na Universidade Federal do Pampa, Campus Jaguarão, e que se realiza junto ao trabalho de estudantes bolsistas - traduzir para a língua portuguesa obras de autores rio-platenses que caracterizam o ambiente regional pampiano em suas narrativas. Com esse intuito e procurando compreender de forma apropriada e significativa diferentes abordagens da literatura produzida sobre o pampa, junto à leitura dos textos literários, são estudados conceitos teóricos sobre o Regionalismo, a Gauchesca, a Fronteira e a Tradução. 
Como prática do trabalho, visando conhecer experiências de outros tradutores e, também, definir um glossário de termos regionalistas utilizados em espanhol e em português, são comparados textos de escritores argentinos e uruguaios já traduzidos para o português e, no caminho inverso, narrativas de autores sul-rio-grandenses com publicação em língua espanhola. Isso possibilita, além de facilitar a pesquisa, construir referências que darão suporte para as escolhas e decisões na solução de casos que poderiam ser mais questionados na sua realização.

Em etapa seguinte, experimentando o ato tradutório, é tomada como objeto de estudo a obra de José Monegal (1892-1968), escritor uruguaio que, durante duas décadas, na segunda metade do século passado, publicou contos em seções literárias de jornais de Melo e Montevidéu, muitos deles hoje reunidos em diferentes edições. Nos textos de Monegal, há uma linguagem composta por regionalismos e marcas de oralidades, exigindo, na tradução para a língua portuguesa, recriações que acentuem marcas fronteiriças, uma vez que esse é outro aspecto presente nas suas narrativas. Dessa forma, intencionalmente, procura-se registrar nas traduções marcas que evidenciam coloquialidades presentes em Jaguarão, cidade que faz fronteira com o território uruguaio e onde estão localizados cursos de Letras da Universidade Federal do Pampa.

Com personagens ambientadas na paisagem pampiana da virada do século XIX para o XX, José Monegal desenvolve uma literatura gauchesca que se opõe à tradição mítica e heróica idealizada pela ficção do período romântico, uma vez que trabalha com o humor e o grotesco, porém apontando sempre o respeito à figura que caracteriza o habitante dos pagos pampianos, como se verifica no diálogo que ele inventou com uma personagem do seu conto Aire libre y pulpa gorda:

- Digamé: ¿no es usté el que escribe del campo, de la sierra, del monte, del gaucho? - Sí señor; son esos, el medio y tipo de mi agrado.

- Pa bien de hacer eso ha tenido que cumplir el mesmo camino que yo hice, pero pa atrás, ¿no es así?

- Seguramente.

- Usté, don, ha tratao, y trata, de que el gaucho no muera. Cada tanto nos resucita en letra y figura: unos güenos, otros malos, los de por aquí alegres, los de por allá tristes; honraos, ladrones, guapos, maulas, legales, falsos, ladinos, abombaos, cinchadores, haraganos, viejos, mozos, gurises, mujeres y varones, blancos y negros...

- Es así mismo, señor.

- Y habiendo metido tantos en esa procesión le faltan mucho más, ¿no?

[...] Y yo lo oía absorto. Hubo un desfile de picardías, de heroísmos, de sacrificios, de disipaciones: desde la ingenuidad de un verso en el pericón, hasta la tragedia de un desafio; desde el agobio de los caminos bajo el chirriar de los ejes hasta el esparcimiento en el juego de sortijas. Y el contrapunto de la payada, el desafio de la penca, el amansamiento de un potro, el arreo de la tropa, el cruce de los ríos embravecidos, la carne bajo el sol, o la luna, o la helada, o el viento. Lanzas, tabas, 
facones, naipes... y una soberbia gallardía por sobre todo esto; y todo esto en un inmenso drama de vida (MONEGAL, 1967, p. 145).

As palavras desse fragmento do conto dão a dimensão exata do conteúdo das narrativas de José Monegal, escritor que soube aprofundar as experiências, o imaginário e os conflitos da vida dos habitantes do campo. O professor e crítico literário Pablo Rocca avalia que os contos de José Monegal "encarnan un ideal o un arquetipo (el héroe, el villano) o un rasgo bien subrayado de la vida social (el desvalido, el prepotente) o una subclase en el entramado social (estanciero, peón, bolichero)" (ROCCA, 2006, p. 12), o que evidencia um profundo conhecimento do caráter psicológico da figura do gaúcho.

As narrativas de José Monegal tiveram difusão por meio de suplementos culturais de jornais, primeiramente no El Deber Cívico, de sua cidade natal, Melo, e depois por um periódico de circulação nacional no Uruguai, El Día, de Montevidéu. Foram publicadas semanalmente e ininterruptamente, sempre aos domingos, entre os anos de 1950 e 1968. É possível reconhecer, assim, que esse escritor desfrutou de grande popularidade, pois se avalia que, naquela época, a tiragem de um jornal chegava a 80.000 exemplares. Rocca chama a atenção para o fato de que

[...] lo popular en Monegal funciona en una intersección que imbrica, por un lado, seres que se presentan como arquetípicos de ese medio rural y, por otro, las posibilidades de conquistar a través de la prensa masiva a un lector no especializado, pero entrenado por la tradición en que se inscribe este narrador para aceptar y celebrar ese tipo de representaciones (ROCCA, 2006, p. 16).

Curioso notar é que o autor não se dedicou a publicar seus contos em livros, pois somente "[...] al final de su vida y a instancias de sus editores, recogió en algunos volúmenes tan dilatada labor que totalizaría unos 350 relatos" (ROCCA, 2006, p. 15). Assim, 12 cuentos, seu livro de estreia, foi publicado em 1963; três anos depois apareceu Cuentos; e no ano de 1967 surgiram os livros Nuevos cuentos e Cuentos escogidos. Antes disso, porém, José Monegal já era conhecido como escritor de romances, pois Memorias de Juan Pedro Camargo foi publicado em 1958 e Nichada, apuntes de un indio de la selva ecuatorial foi impresso pela Editorial Nueva América em 1938.

Após 1968, ano de sua morte, outras coletâneas foram organizadas: Cuentos de bichos (1973); El tropero macabro y otros cuentos (1978); Cuentos de milicos y matreros (1993); Cerrazón y otros cuentos (2007) eLa receta del negro Antenor y otros cuentos (2012). Editados em livro, portanto, existem 150 contos de José Monegal, muitos repetidos de uma publicação a 
outra, além de alguns também terem aparecido em antologias, como em Cuentos uruguayos magistrales (1980) e Antología del cuento criollo (2001).

Mesmo tendo sido originalmente escritos para colunas de jornal, seus textos, como gênero literário, respeitam estruturas do conto. Isso se deve à aprendizagem que obteve pela imposição da restrição do espaço da página do suplemento literário do periódico, uma vez que soube calcular a intensidade de cada adjetivo, de cada descrição e de cada diálogo para manter a tensão dos relatos e a atenção do leitor, utilizando-se para isso, como ressalta Pablo Rocca, de técnicas como

[...] diferentes operadores de principio, introducidos desde la primeras frases o suspendiendo su esclarecimiento hasta las últimas líneas; [...] la imitación de la voz y los tonos de un narrador oral, como el de los fogones campesinos. [...] Así aprendió la técnica del cuento en la tradición de Edgar Allan Poe, la que cuida de la "construcción" y el "efecto" del hecho narrado, desechando lo decorativo, la que se obsesiona por la comunicación "natural” con un lector de masas (ROCCA, 2006, p. 24).

Neste trabalho, em sentido ilustrativo do projeto, é analisada, por meio de aporte teórico, uma prática da tradução literária de Arquetipo, conto que é nutrido por um humor que foge da nostalgia e do costumbrismo da cor local. Diferente de uma idealização mítica do gaúcho, tão presente em muitos autores regionalistas, esse texto investe na representação do mamado, do borracho, do sujeito que bebe para além da conta, acentuando uma picardia que também representa o gaúcho, demonstrando outras e mais amplas características do peão do campo. Destaca-se, assim, a universalização de um caráter regional, o que viabiliza a importância da tradução, pois os conflitos ambientados em uma temática local podem despertar interesse a leitores das mais variadas culturas, não apenas para aqueles que conhecem o meio regional pampiano.

A importância de existirem traduções literárias está na ideia de que elas estabelecem relações que aproximam povos e culturas e, também, por meio desses contatos, possibilitam interferências nas literaturas da língua de chegada, uma vez que têm a capacidade de inserir formas e conceitos nas tradições literárias receptoras, contribuindo com outros modelos, outras estéticas e outras ideias. Desse modo, entende-se que a tradução trabalha não apenas com a diversidade de línguas, mas também, como já apontou Octavio Paz (2013), com uma diversidade de sociedades, em que cada civilização é um mundo e cada linguagem traduzida é uma visão de mundo. 
Houve tempos em que se definia que uma tradução bem realizada seria aquela que atingisse uma equivalência entre as línguas de partida e de chegada. Atualmente, existe uma rejeição a esse pensamento, pois ele confere uma concepção estável da língua, passível de ser "transportada" por meio de de contornos claros e lógicos. Pressupõe, assim, que ocorram paralelismos automáticos e normativos entre línguas diferentes. No entanto, no exercício tradutório, comprova-se que existem muitas "dificuldades de se manter a chamada integridade original de uma obra literária" (ANTUNES, 1991, p. 1). É possível afirmar, então, que não há como reproduzir exatamente igual no texto traduzido o que tenha sido colocado originalmente.

Por essa questão da diferença dos textos, muitas vezes estabeleceram-se hierarquias entre os originais e suas traduções, situadas estas como inferiores e devedoras em relação aos primeiros, uma vez que estariam deformando a elaboração textual do autor. Assim, cria-se o juízo de que a tradução é pior do que o original. Nessa concepção, teríamos o entendimento da intraduzibilidade literária.

Reconhece-se que, ao se traduzir, pode haver perdas. Porém, ao bom tradutor, cabe o esforço de buscar compensações para eventuais prejuízos. Isso exige que se tenha, no mesmo 160 parâmetro do autor do texto a ser traduzido, um processo de criação artística.

Em nota que consta na primeira edição de Serafim Ponte Grande, Oswald de Andrade, dentro do seu espírito antropofágico, brincava com a seguinte advertência: "direito de ser traduzido, reproduzido e deformado em todas as línguas" (ANDRADE apud ANTUNES, 1991, p. 1). Há, nesse tom jocoso, um forte conceito do que venha a ser a tradução literária, reconhecendo-se que é "impossível uma única tradução perfeita de uma obra literária." (ANTUNES, 1991, p. 3). O que existem são possíveis versões de um texto, ou seja, podem ocorrer inúmeras traduções de um texto dentro de uma mesma língua de chegada, mas nenhuma poderá ser considerada a ideal. Talvez possa existir alguma que seja a melhor, mas isso não invalida a possibilidade haver outras versões.

Podemos afirmar que o processo de tradução de textos literários é, antes de tudo, um processo de leitura, de criação e de escolhas, isto é, não cabe ao tradutor realizar em outra língua o mesmo texto da obra literária original. Assim, a tarefa que se exige do tradutor é buscar a forma mais próxima dos efeitos de representação presentes no texto de partida, sabendo-se que o seu produto será - não há como ser diferente - uma "traição" do texto original. Entende-se aqui a traição no sentido da metáfora traduttore-traditore, ou seja, sentido no qual se realiza uma invenção, conforme aponta Armindo Trevisan: "só existiria traição onde existe linguagem, intenção explícita (ou implícita) de se fazer literatura. Na medida em que a metáfora está na 
base de todo fenômeno artístico, a tradução, para ser ela mesma, necessita superar-se a si mesma, atingindo a metáfora" (TREVISAN apud ANTUNES, 1991, p. 4). Ainda segundo palavras de Trevisan, "a essência da tradução consiste, pois, em propor um símbolo, ultrapassando-o na direção da metáfora" (TREVISAN apud ANTUNES, 1991, p. 4). Esse direcionamento da metáfora é um diálogo com o texto original, uma vez que, como se refere Octavio Paz, ele permanece, pois "está presente sempre porque a tradução, sem dizê-lo, o menciona constantemente ou o converte num objeto verbal que, ainda que diferente, o reproduz: metonímia e metáfora” (PAZ, 2013, p. 88).

Considerando a capacidade criadora da tradução, podemos associá-la ao que nos revela Rosemary Arrojo, quando diz:

toda tradução, por mais simples e breve que seja, revela ser produto de uma perspectiva, de um sujeito interpretante e, não meramente, uma compreensão "neutra" e desinteressada ou um resgate comprovadamente "correto" ou "incorreto" dos significados supostamente estáveis do texto de partida (ARROJO, 1992, p. 68).

É possível ver, então, que a exigência que se faz ao tradutor é, antes de mais nada, o exercício de uma leitura aprofundada do texto original. Isso possibilitará que o tradutor realize uma análise interpretativa para, depois, proceder suas escolhas de vocabulário e estruturas gramaticais na tarefa da tradução. Dessa forma, seguindo formulação de Gérard Genette, entende-se que "o sentido dos livros está na frente e não atrás, está em nós: um livro não é um sentido acabado, uma revelação que devemos receber, é uma reserva de formas que esperam seu sentido" (GENETTE apud ANTUNES, 1991, p. 7) por meio da leitura. Por sua vez, uma leitura aprofundada exigirá do tradutor conhecimentos culturais tanto da língua de partida quanto da de chegada. Assim, poderá, de maneira mais apropriada, solucionar problemas, tais como gírias, provérbios ou expressões idiomáticas, que lhe sejam apresentados durante a prática tradutória.

Diante dessas considerações, avaliamos que a tradução não deva ser um espelho do texto original - ideia que prosperava há poucas décadas -, mas sim uma revelação das infinitas possibilidades desse texto, abrindo espaço para a criatividade e revelando a riqueza da multiplicidade de leituras oferecidas por esse texto fonte.

Para exemplificar uma prática de tradução, foram identificadas várias ocorrências linguísticas, de diferentes níveis, que criam dificuldades para realizar a versão para a língua portuguesa do conto aqui selecionado. Em Arquetipo, existe a descrição de uma paisagem rural típica do interior do Uruguai, mostrando aspectos da vida, dos costumes e das tradições de um 
povo campeiro. Para isso, o autor utiliza uma linguagem própria dessa região, repleta de coloquialismos nutridos por termos gauchescos, o que evidencia variações da língua que caracterizam indivíduos do meio rural. Porém, mais do que reproduzir essa linguagem de José Monegal, idealiza uma representação da fala do gaúcho. Para Pablo Rocca, "la gauchesca y sus derivaciones - llámense 'criollismo', 'nativismo' o más globalmente 'posgauchesca' - edifican un 'lenguaje técnico', cuya artificiosidad es homóloga a la estandarización y homogeneización de la lengua oficial que adopta el Estado" (ROCCA, 2009, p. 14). No entanto, o professor e crítico uruguaio, referindo-se aos autores de literatura gauchesca, não nega

[...] la dependencia o la pretendida mimetización de este discurso con las formas de habla propiamente camperas. Ciertas evidencias fonéticas en el habla de la zona pampeana demuestran que Bartolomé Hidalgo y sus seguidores inventan mucho, sobre todo a nivel de la estructuración formal e ideológica del mensaje, pero buscando acercarse el máximo posible a la oralidad de aquellos criollos con los que convivían (ROCCA, 2009, p. 14, grifo nosso).

Assim, reconhecendo que o conto Arquetipo é uma produção escrita que se vale de uma cultura oral, percebe-se que, para traduzir, não é suficiente compreender a língua espanhola e a língua portuguesa. Mais do que isso, faz-se necessário saber sobre o universo cultural retratado por José Monegal. Costumes e tradições dessa cultura também estão presentes na literatura regional sul-rio-grandense. Dessa forma, as coloquialidades e estéticas que aparecem nas obras dos regionalistas do Rio Grande do Sul poderão ser um parâmetro para buscar soluções para as dúvidas encontradas no desenvolvimento da tradução.

Outro recurso é a manutenção de termos da língua espanhola no texto traduzido para representar oralidades, pois, como avalia Pablo Rocca, "la gauchesca transformó la frontera estatal en un espacio poroso, logró tender puentes y mover barreras contra la voluntad del discurso del poder oficial a cualquier lado de la línea" (ROCCA, 2009, p. 14). Com isso, o leitor é forçado a participar da construção do texto, buscando, ele mesmo, uma significação por meio dos seus conhecimentos da cultura e da língua espanhola.

Pretende-se, desse modo, dar ênfase ao espaço fronteiriço no qual estamos inseridos e que define o local de realização da tradução proposta, pois este é um território em que existem interferências do idioma espanhol no idioma português e vice-versa.

Assim como há vocabulário de ambos os idiomas na fronteira, também existem estruturas sintáticas que conformam uma linguagem própria dessa região. Por isso, o texto traduzido, identificado com marcas da fala jaguarense, possui construções que não são comuns na língua portuguesa presente em outras regiões do Brasil. 


\section{Transcriações na tradução do conto Arquétipo}

Arquetipo é a narrativa que abre 12 cuentos, o primeiro livro de contos de José Monegal e que foi publicado no ano de 1963. Esse mesmo texto também faz parte das coletâneas que compõem as obras Cuentos escogidos e Cerrazón y otros cuentos, de 1967 e 2007, respectivamente. Mas a publicação original de Arquetipo se deu no Suplemento Dominical de El día, jornal de Montevidéu, no dia 19 de novembro de 1961. Nessa história, relata-se o caso de um tipo que se acorda lentamente, depois de uma noite de bebedeiras. Ele se encontra no meio do campo, mas vai se dando conta do seu estado aos poucos até compreender que, embriagado, dormiu no caminho, antes de voltar para casa. Muitas são as dificuldades com que se depara para seguir para o seu rancho, decidindo então por se dirigir novamente ao comércio onde havia se alcoolizado na noite anterior.

$\mathrm{Na}$ tradução que realizamos, esse conto foi intitulado Arquétipo e, a seguir, serão enumerados alguns dos casos que exigiram um esforço maior para encontrar a solução mais adequada dentro dos propósitos definidos, isto é, dar conta de uma tradução que cria um texto - ou transcria, conforme concepção de Haroldo de Campos (1991) -, priorizando a significação interpretada na leitura do conto de José Monegal. Com essa intenção, reconhecemos que a tradução efetuada é uma das possíveis leituras, demonstrando uma das possibilidades da multiplicidade que um texto literário apresenta.

Os casos que comentaremos são:

\section{a) [...] era algo fijo, intenso, como para arrollarse y llorar por lo largo. \\ [...] era algo agudo, intenso, como para se dobrar e chorar a lo grande.}

Uma tradução literal não alcança o significado da expressão, pois o termo "largo" tem a palavra "comprido" como seu equivalente em português. Dessa maneira, foi preciso buscar alguma expressão que apontasse a ideia de chorar bastante. Em uma primeira versão, foi escolhida a construção "chorar a varrer", forma de utilização reconhecida na língua portuguesa e que mantêm o sentido coloquial do texto de José Monegal. Porém, em uma revisão da tradução, optou-se por empregar vocábulo presente na obra O príncipe da vila, de Cyro Martins, narrativa em que o autor sul-rio-grandense faz uso de uma linguagem que entrevera o português com expressões típicas dos castelhanos, valendo-se da língua espanhola para enfatizar modos da fala de um tipo fronteiriço. No romance de Cyro Martins, a voz narrativa, para dizer que os homens falavam bastante, menciona: "de putarias, sim, charlavam a lo grande" (MARTINS, 
1987, p. 14). Assim, valendo-se da forma empregada pelo autor de $O$ príncipe da vila, na tradução de Arquétipo é mantido o idioma espanhol, mas são alterados os termos na intenção de aproximar o texto traduzido ao leitor brasileiro, uma vez que "a lo grande" é de mais fácil compreensão do que "a lo largo".

b) [...] caminando sobre un calamotal, de la pulpería del negro Polonio [...]

[...] caminhando sobre o lamaçal da pulperia do negro Polônio [...]

Segundo denotação que aparece no Dicionário da cultura pampeana sul-rio-grandense, de Aldyr Garcia Schlee, "pulperia" significa um "comércio limitado de secos e molhados, com livre fornecimento de bebidas, instalado geralmente no campo, ao longo de caminhos e em lugares estratégicos da campanha" (SCHLEE, 2019, p. 748). O mesmo autor, em Vocabulário de João Simões Lopes Neto, descreve: "estabelecimento comercial da campanha antiga, maior do que um bolicho e que servia de armazém, loja, taberna e casa de jogo" (SCHLEE, 2011, p. 96). Como esse é um termo usado com muita frequência em textos regionalistas gauchescos, 164 preferiu-se manter a forma original, assim como faz Darcy Azambuja no conto Contrabandista: “[...] ilhara-os do outro lado da fronteira, na pulperia do Aguirre, a comer carne assada e jogar o truco" (AZAMBUJA, 2005, p. 125).

c) - No hay duda o-se dijo-es mi moro tapao de helada.

- Não há dúvida - se disse - é meu mouro branquito de geada.

Na primeira versão da tradução, não encontrando uma forma semelhante para dar conta da oralidade utilizada por José Monegal, foi pensado "tapado de geada". Porém, decidiu-se explorar outra estrutura para priorizar marcas da fala. Assim, houve a opção por um termo no diminutivo -ito, indicando um linguajar coloquial identificado com a cultura fronteiriça. Nessa escolha, evidenciando a cor provocada pela intempérie climática, foi mantido o sentido de que o animal ficou coberto do gelo provocado pelo frio e pela umidade da noite.

d) - ¡Gran siete -murmuró- toyhecho vidrio, de ésta no salgo!

- Que locura!- murmurou - tôvirado em vidro, desta não saio! 
“Gran siete" não possui uma tradução literal para a língua portuguesa. Em um primeiro momento, pensou-se que a melhor solução seria "grande coisa". Porém, aprofundando a leitura, interpretou-se que a manifestação da personagem era de espanto, diferente do tom de desprezo contido na expressão inicialmente conjecturada. Desse modo, escolheu-se fazer a tradução por “que locura”, entendendo ser essa a expressão que melhor dá conta do significado do texto de partida, além de enfatizar uma marca de oralidade com presença do espanhol e muito jaguarense, o que enfatiza o lugar de realização da tradução. Na continuação da fala da personagem, foi utilizado "tô virado", forma habitual da conversação, mantendo a oralidade e o sentido registrado no texto em espanhol.

e) Se las había sacado, pues. ¿Cómo no vio, entonces, que le faltaba el pie derecho? É certo, então, que as tinha tirado. Como não viu que le faltava o pé direito?

$\mathrm{Na}$ tradução desse fragmento - que se refere ao ato da personagem ter descalçado as botas e que, naquele momento, ainda meio dormido, pensava que tinha perdido um dos pés, pois não sentia essa parte do seu corpo -, houve a troca da conjunção "pues" pela forma conclusiva "é certo". Mas, para preservar o estilo adotado pelo autor do conto, foi trazido o advérbio "então" para o primeiro período, mantendo-se a alusão a uma reflexão da personagem. No período interrogativo, assim como em outras passagens do texto, conservou-se o uso de "le", como fazem muitos autores regionalistas, como, por exemplo, Tabajara Ruas, em Netto perde sua alma: “- Vosmecê por aqui, sargento. Como le vai?” (RUAS, 2005, p. 35).

\section{f) [...] él se iba durmiendo beatíficamente. \\ [...] ele ia se dormindo beatificamente.}

Neste caso, aproximando-se da estrutura gramatical da língua espanhola, foi mantido o pronome com sua função reflexiva. Esta situação específica, conforme aparece no texto, não é um uso comum em português. No entanto, em Jaguarão, local de enunciação desta tradução, é uma forma de uso corrente. Desse modo, escolhendo apontar o caráter próprio desta região, houve como propósito apresentar uma construção com marca identitária local.

\section{g) [...] lo que necesito es que me dejen ande toy [...] \\ [...] o que necessito é que me deixem donde tô [...]}


A forma escrita por José Monegal traz um uso oral para o texto, representando um falar campeiro da personagem. Não foi encontrada semelhante expressão na língua portuguesa, então a opção foi colocar um termo em espanhol para simular a coloquialidade, entendendo que esse vocábulo respeita o modo da fala rural do gaúcho, sobretudo por fazer referência a falas presentes na fronteira, onde os espanholismos são habituais.

\section{h) - ;Güeno, güeno, no se empine tanto! \\ - Bueno, bueno, não se empine tanto!}

Como no caso apontado anteriormente, aqui também existe uma intencionalidade do uso de uma linguagem coloquial. Assim, buscou-se a mesma solução empregada antes, demonstrando um aspecto cultural próprio da fronteira, espaço em que o espanhol e o português se misturam.

Outras alterações foram necessárias para realizar a tradução do conto Arquétipo, mas o objetivo aqui foi apresentar apenas algumas das situações, entendendo que elas demonstram o 166 direcionamento do propósito e das ponderações que determinaram as escolhas.

Outros tradutores, muito provavelmente, teriam encontrado alternativas diferentes no seu processo tradutório. Isso não quer dizer que as soluções aqui apresentadas não estejam corretas ou, ao contrário, sejam definitivamente as mais acertadas. As escolhas feitas representam uma das possíveis leituras do conto, uma interpretação, aquela que manifesta a bagagem cultural do leitor/tradutor e que expõe marcas da uma identidade jaguarense e fronteiriça.

\section{Considerações finais}

Muitas vezes, o conceito de fronteira é confundido ou até identificado como um limite. Essa ideia reconhece apenas separações que impedem os movimentos e ignoram os contatos que articulam interfaces, imbricamentos e recomposições em que identidades e alteridades se interpenetram. No entanto, a compreensão da fronteira como um espaço intervalar - um lugar da convivência da diversidade - permite que o mesmo e o outro se configurem em consonâncias, interagindo em amplitudes que enriquecem culturas e permitem abrangências sem restrições. Pois é nesse caminho de aberturas que podemos compreender a tradução literária, uma vez que ela, tal como pontes que aproximam as margens de um rio, mostra outras possibilidades, outras formas e outras leituras de um mesmo texto. 
Sob esse enfoque é que a pesquisa Fronteiras da tradução literária desenvolvida na Universidade Federal do Pampa, Campus Jaguarão, vem realizando a tradução da obra de José Monegal, autor que expõe parâmetros não conservadores da figura do gaúcho na literatura regional pampiana. Ao propor recriações nos contos desse escritor uruguaio, respeitando intenções e marcas regionais e coloquiais presentes nos textos de partida, procura-se integrar a produção de Monegal ao acervo dos leitores de língua portuguesa, aproximando tradições literárias de um lado e outro das linhas que demarcam o Brasil e os países do Prata.

A tradução torna-se, desse modo, um lugar privilegiado para a desconstrução dos muros imaginários que buscam separar idiomas, culturas e povos. Ressaltando as porosidades da fronteira, a tradução se coloca no entre-lugar em que equivalências não encontram espaço, pois são justamente as divergências que se impõe, tal como o "bueno" do exemplo explicado anteriormente, pois esse termo não está presente no conto de partida, mas se mostra tradução perfeita para o texto em língua portuguesa. Dessa forma, conforme a teoria da tradução reconhece, ficam evidenciadas as porosidades, os trânsitos e os contrabandos literários e linguísticos disseminados na fronteira, território do encontro das diferenças.

\section{REFERÊNCIAS}

ANTUNES, Benedito. Notas sobre a tradução literária. Revista Alfa, São Paulo, v. 35, p. 1$10,1991$.

ARROJO, Rosemary. As questões teóricas da tradução e a desconstrução do logocentrismo: algumas reflexões. In: ARROJO, Rosemary. (org.). O signo desconstruído: implicações para a tradução, a leitura e o ensino. Campinas: Pontes, 1992. p. 67-79.

AZAMBUJA, Darcy. Contrabandista. In: AZAMBUJA, Darcy. Contos escolhidos. Porto Alegre: Já, 2005.

CAMPOS, Haroldo de. Tradução e reconfiguração do imaginário: o tradutor como transfingidor. In: COUTHARD, Malcolm (org). Tradução: teoria e prática. Florianópolis: UFSC, 1991. p. 17-31.

MARTINS, Cyro. O príncipe da vila. Porto Alegre: Movimento, 1987. MONEGAL, José. Cuentos escogidos. Montevidéu, Banda Oriental: 1967.

ROCCA, Pablo. La última frontera (El caso José Monegal). Revista Hologramática literaria - Facultad de Ciencias Sociales - UNLZ, ano I, n. 2, p. 6-32, 2006.

ROCCA, Pablo. Acerca de las representaciones de lo rural. Revista Tradiciones rurales. Comisión del Patrimonio Cultural de la Nación. Montevidéu, p. 14-22, 26 e 27 de setembro de 2009. RUAS, Tabajara. Netto perde sua alma. Rio de Janeiro: Record, 2005. 
SCHLEE, Aldyr Garcia. Vocabulário de João Simões Lopes Neto. Pelotas: Fructos do Paiz, 2009.

SCHLEE, Aldyr Garcia. Dicionário da cultura pampeana sul-rio-grandense. v. II. Pelotas: Fructos do Paiz, 2019.

PAZ, Octavio. Tradução e metáfora. In: PAZ, Octavio. Os filhos do barro. Traduzido por: Ari Roitman e Paulina Wacht. São Paulo: CosacNaify, 2013. p. 85-105.

* Carlos García RIZZON - Doutor (2011) e Mestre (2005) em Letras pela Universidade Federal do Rio Grande do Sul. Licenciado em Letras (1992) pela mesma instituição. Professor na Universidade Federal do Pampa, campus Jaguarão. Jaguarão, Rio Grande do Sul, Brasil.

Currículo acadêmico: http://lattes.cnpq.br/0346145295521362

ORCID: https://orcid.org/0000-0003-0950-3432

E-mail: rizzoonn@gmail.com 